\title{
Frontal and Temporal Dopamine Release during Working Memory and Attention Tasks in Healthy Humans: a Positron Emission Tomography Study Using the High-Affinity Dopamine $\mathrm{D}_{2}$ Receptor Ligand $\left[{ }^{11} \mathrm{C}\right] \mathrm{FLB} 457$
}

\author{
Sargo Aalto, ${ }^{1,2}$ Anna Brück, ${ }^{1}$ Matti Laine, ${ }^{3}$ Kjell Någren, ${ }^{1}$ and Juha 0. Rinne ${ }^{1,4}$ \\ ${ }^{1}$ Turku PET Centre and ${ }^{2}$ Centre for Cognitive Neuroscience, University of Turku, FIN-20014 Turku, Finland, ${ }^{3}$ Department of Psychology, Åbo Akademi \\ University, FIN-20500 Åbo, Finland, and ${ }^{4}$ Department of Neurology, Turku University Hospital, FIN-20520 Turku, Finland
}

\begin{abstract}
Experimental studies on animals have shown that dopamine is a key neurotransmitter in the regulation of working memory (WM) functions in the prefrontal cortex. In humans, blood flow studies show prefrontal involvement in WM functions, but direct evidence for the involvement of the dopaminergic system in WM is lacking. Using positron emission tomography with a recently developed high-affinity dopamine $\mathrm{D}_{2}$ receptor tracer, $\left[{ }^{11} \mathrm{C}\right] \mathrm{FLB} 457$, we explored frontal, temporal, and parietal $\mathrm{D}_{2}$ receptor availability in 12 healthy volunteers while they were performing verbal WM and sustained attention tasks. During the performance of both tasks, reduced $\mathrm{D}_{2}$ receptor availability was observed in the left ventral anterior cingulate, suggesting an attention or arousal-related increase in dopamine release during these tasks. Compared with the sustained attention task, the verbal WM task reduced $\mathrm{D}_{2}$ receptor availability in the ventrolateral frontal cortex bilaterally and in the left medial temporal structures (amygdala, hippocampus), suggesting that dopamine release in these regions might have a specific role in WM. In addition, correlation analyses indicated that increased dopamine release in the right ventrolateral frontal cortex and the left ventral anterior cingulate during the WM task was associated with faster and more stable WM performance, respectively. Our results indicate that regionally specific components of the frontotemporal dopaminergic network are functionally involved in WM performance in humans.
\end{abstract}

Key words: positron emission tomography; PET; [ $\left.{ }^{11} \mathrm{C}\right] \mathrm{FLB} 457$; dopamine; working memory; attention

\section{Introduction}

Recent research on primates has started to unveil the dynamics of chemical neuromodulation in cognition. Single-cell recordings during delayed response tasks have shown that working memory (WM) is associated with sustained prefrontal neuronal activity that can be modulated by dopaminergic manipulations (Goldman-Rakic, 1996). There is also evidence in humans for modulation of WM and other cognitive functions by dopaminergic drugs (Müller et al., 1998; Mehta et al., 1999). Microdialysis studies have demonstrated that WM-like tasks induce dopamine release in the prefrontal cortex in monkeys (Watanabe et al., 1997) and rats (Phillips et al., 2004) and that reading and WM tasks induce dopamine release in the amygdala in epileptic patients (Fried et al., 2001). Regional cerebral blood flow (rCBF)

Received Feb. 13, 2004; revised Jan. 21, 2005; accepted Jan. 21, 2005

This work was supported financially by a grant from the Academy of Finland (21501), by clinical grants (Erityisvaltionosuus-hankerahoitus) from the Turku University Hospital (Turku, Finland), by the Emil Aaltonen Foundation, and by the Turku University Foundation. We thank Dr. H. Tanila for valuable comments on this manuscript. The technical assistance by the staff of the Turku PET Centre is gratefully acknowledged. The study used voxel analysis methodology validated in the Drug 2000 project, funded by the National Agency of Technology, Finland.

Correspondence should be addressed to Sargo Aalto, Turku PET Centre, University of Turku, P.0. Box 52, FIN20521 Turku, Finland. E-mail: sargo.aalto@utu.fi.

DOI:10.1523/JNEUROSCI.2097-04.2005

Copyright $\odot 2005$ Society for Neuroscience $\quad$ 0270-6474/05/252471-07\$15.00/0 measurements during verbal working memory performance in healthy humans have consistently revealed increased blood flow in the prefrontal cortex and the inferior parietal cortex (for review, see Cabeza and Nyberg, 2000). However, these blood flow changes do not give any information of the underlying neurotransmitter systems, and direct evidence of the dopaminergic regulation of WM in healthy humans is lacking.

Positron emission tomography (PET) with benzamide $\left[{ }^{11} \mathrm{C}\right]$ raclopride enables detection of dopamine release in vivo in different experimental settings (Koepp et al., 1998; Kaasinen et al., 2004; Pruessner et al., 2004). This is based on the binding competition principle: when the endogenous ligand dopamine competes with the radioligand for binding sites, the increase in dopamine concentration results in a decrease of binding of the radioligand (for review, see Laruelle, 2000; Laruelle and Huang, 2001). However, because of the low affinity of $\left[{ }^{11} \mathrm{C}\right]$ raclopride, this methodology does not enable reliable quantification of dopamine $\mathrm{D}_{2}$ receptors in the cortical regions (Hirvonen et al., 2003). The recently developed high-affinity dopamine $D_{2} / D_{3}$ receptor tracer, $\left[{ }^{11} \mathrm{C}\right] \mathrm{FLB} 457$, on the other hand, allows quantification of $\mathrm{D}_{2}$ receptors in cortical regions (Farde et al., 1997). Because the competition between a radioligand and an endogenous ligand does not depend on the affinity of the radioligand (Laruelle and Huang, 2001), [ $\left.{ }^{11} \mathrm{C}\right] \mathrm{FLB} 457$ is making it feasible to 
detect changes in the dopamine concentration in the cortical regions, which is also supported by recent studies in monkeys (Chou et al., 2000) and in humans (Hagelberg et al., 2004). The theoretical framework behind the competition principle, namely, the occupancy model, has not been accepted without critique (for review, see Laruelle, 2000). Accordingly, alternative dopaminemediated explanations other than direct competition between dopamine and radioligand, such as agonist-mediated receptor internalization, might be needed to explain the results of competition experiments. Nevertheless, because an increased dopamine concentration at least indirectly decreases the binding of benzamides (Laruelle and Huang, 2001), the limitations of the occupancy model as such are not of concern when exploring the involvement of dopamine release in human cognition with $\left[{ }^{11} \mathrm{C}\right]$ FLB 457.

The aim of the present study was to explore whether sustained attention or WM tasks induce a decrease in the binding of $\left[{ }^{11} \mathrm{C}\right] \mathrm{FLB} 457$ in the frontal, temporal, and parietal regions, an effect that would at least indirectly indicate task-related dopamine release. Using 12 healthy volunteers, three $\left[{ }^{11} \mathrm{C}\right] \mathrm{FLB} 457$ scans were performed in a within-subject counterbalanced design including a resting baseline, a sustained attention task, and a WM task. We hypothesized that task-induced decreases in the binding of [ $\left.{ }^{11} \mathrm{C}\right] \mathrm{FLB} 457$ would be detected in the regions suggested to be involved in attention and WM.

\section{Materials and Methods}

Subjects. The study protocol was approved by the joint ethical committee of the University of Turku and Turku University Hospital. Twelve healthy, right-handed, nonsmoking male volunteers were recruited after written informed consent. The age, weight, and height of the subjects were $24.7 \pm 4.9$ years, $70.1 \pm 10.2 \mathrm{~kg}$, and $177.5 \pm 7.3 \mathrm{~cm}$ (mean $\pm \mathrm{SD}$ ), respectively. To exclude structural abnormalities of the brain and to obtain anatomical brain images, each individual had a 1.5 tesla brain magnetic resonance imaging (MRI) (GE Signa; General Electric Medical Systems, Milwaukee, WI) scan with a fast spoiled gradient echo sequence (repetition time, $11.3 \mathrm{~ms}$; echo time, $4.2 \mathrm{~ms}$; flip angle, $20^{\circ}$; matrix, $256 \times$ 256; one acquisition), which resulted in 1241.2 -mm-thick axial images with no interslice gaps.

PET data acquisition. The PET experiments were performed using a whole-body PET scanner (GE Advance; General Electric Medical Systems) with 35 slices of $4.25 \mathrm{~mm}$ thickness covering the entire brain. The PET camera was run in the three-dimensional mode with scatter correction based on attenuation information and the deconvolution method (Bergström et al., 1983). The performance characteristic tests made on this camera indicate that the transaxial spatial resolution at a radius of 10 $\mathrm{cm}$ in midplanes is $6 \mathrm{~mm}$ in the radial direction and $5 \mathrm{~mm}$ in the tangential direction, and the axial resolution is $6.5 \mathrm{~mm}$ (Lewellen et al., 1996). The preparation of $\left[{ }^{11} \mathrm{C}\right]$ FLB 457 and the determination of the radiochemical purity and specific radioactivity of the radioligand were performed as described previously (Vilkman et al., 2000).

Each subject was scanned three times during the same day using a 69 $\min \left[{ }^{11} \mathrm{C}\right] \mathrm{FLB} 457$ scanning period and a minimum $2 \mathrm{~h}$ interscan interval corresponding to approximately six half-lives of ${ }^{11} \mathrm{C}$. This interval is generally considered adequate for ${ }^{11} \mathrm{C}$, although the duration of the potential occupancy effect of the cold ligand (Olsson et al., 2004) is not clear. At the resting baseline, the injected dose, the specific activity, and the mass of injected ligand per body mass were $202 \pm 2 \mathrm{MBq}, 78.1 \pm 5.3$ $\mathrm{MBq} / \mathrm{nmol}$, and $14.6 \pm 1.1 \mathrm{ng} / \mathrm{kg}$, respectively. The corresponding values in the vigilance condition were $203 \pm 1 \mathrm{MBq}, 70.8 \pm 4.7 \mathrm{MBq} / \mathrm{nmol}$, and $16.5 \pm 1.8 \mathrm{ng} / \mathrm{kg}$, and those in the WM condition were $202 \pm 2 \mathrm{MBq}$, $70.7 \pm 7.4 \mathrm{MBq} / \mathrm{nmol}$, and $17.2 \pm 1.9 \mathrm{ng} / \mathrm{kg}$, respectively. The mean values of the injected masses did not differ significantly between the scans [repeated-measures ANOVA (rmANOVA); $F_{(2,22)}=1.01 ; p=0.38$ ]. The behavioral tasks were commenced $120 \mathrm{~s}$ before the injection and continued throughout the duration of the scan. The order of the scans (tasks) was counterbalanced to eliminate possible order effects caused by the tasks as well as residual radioactivity and the residual effects of the mass of the tracer (i.e., the cold ligand).

Behavioral task. Single consonants were presented visually by a personal computer on a projector screen located $\sim 2 \mathrm{~m}$ in front of the subject. Stimulus presentation and data collection via a two-button, righthand, reaction-time key were controlled by reaction-time software. Two task conditions (vigilance, working memory) were used by using similar stimulus sequences and by varying only the task instruction. In the vigilance task (zero-back task), the subject was to press the "yes" button each time the letter X appeared (in 25\% of cases) and otherwise to press the "no" button. In the WM task (two-back task), the subject was to press the yes button each time the consonant was the same as that presented two items previously (in 25\% of cases) and otherwise to press the no button. The two-back task was chosen because our previous study (Haarala et al., 2003) suggested that the high cognitive demands posed by the three-back task make it unsuitable for an hour-long continuous-task setup. Each stimulus was presented for up to $1999 \mathrm{~ms}$ with a $1495 \mathrm{~ms}$ interstimulus interval. In addition, a resting state baseline condition (the subjects lying with their eyes open in the scanner) was included in the design.

Regions-of-interest analysis. The quantification of [ $\left.{ }^{11} \mathrm{C}\right] \mathrm{FLB} 457$ binding was made as described previously (Hagelberg et al., 2004) with minor modifications. Briefly, the dynamic $\left[{ }^{11} \mathrm{C}\right] \mathrm{FLB} 457$ images were realigned (within-subject) using Statistical Parametric Mapping software, version 99 (SPM99; Wellcome Department of Cognitive Neurology, University College London, London, UK) and realignment parameters, which were estimated from the $\left[{ }^{11} \mathrm{C}\right] \mathrm{FLB} 457$ summed images. The individual MRIs were coregistered with the mean image of the realigned summated images of each individual. Regions of interest (ROIs) were drawn using Imadeus software (version 1.5; Forima, Turku, Finland). ROIs were delineated bilaterally according to individual anatomy on the axial MRI slices on the regions suggested to be involved in memory or attentional functions in general or WM in particular (Fried et al., 2001) (for review, see Bush et al., 2000; Cabeza and Nyberg, 2000). ROIs for the anterior cingulate cortex (AC) were subdivided into the ventral (four planes) and dorsal (four planes) divisions in accordance with the suggested functional specialization (Bush et al., 2000). ROIs for the ventrolateral frontal cortex (VLFC; three planes) were delineated on the lowest part of the inferior frontal gyrus, including mainly Brodmann area (BA) 45. ROIs for the dorsolateral frontal cortex (DLFC; three planes), including mainly BA 46 but also the lower parts of BA 9, were delineated on the center of the middle frontal gyrus (for the division of the lateral frontal cortex used, see Fletcher and Henson, 2001). ROIs for the medial temporal lobe (MT; three planes) included both the amygdala and the hippocampus to enhance the reproducibility of measurements (Sudo et al., 2001). ROIs for the inferior parietal lobe (IPL; three planes) were targeted on the supramarginal gyrus (BA 40). The reference region, including mainly gray matter, was drawn on the cerebellar cortex (three planes). The visualization of the ROIs is presented in Figure 1.

$\mathrm{D}_{2}$ receptor availability was quantified as the $\left[{ }^{11} \mathrm{C}\right] \mathrm{FLB} 457$ binding potential (BP) using the reference tissue model (Lammertsma and Hume, 1996; Vilkman et al., 2000). $\mathrm{BP}=f_{2} \times B_{\max } / K_{\mathrm{d}}$, where $f_{2}$ is the free fraction of the free plus nonspecifically bound ligand in the brain, $B_{\max }$ is the receptor density, and $K_{\mathrm{d}}$ is the dissociation constant (for the nomenclature, see Slifstein and Laruelle, 2001). Several methodological publications have found the cerebellar reference methods suitable for calculation of the BP of [ ${ }^{11}$ C]FLB 457 (Olsson et al., 1999, 2004; Vilkman et al., 2000; Ito et al., 2001) (but see Delforge et al., 1999). Although the cerebellum contains some $\mathrm{D}_{2}$ receptors (Hall et al., 1996), yielding a slight underestimation of $\mathrm{BP}$ values in drug occupancy studies, the error caused by this (Olsson et al., 2004) in our behavioral study is less than the error demonstrated in test-retest studies (Vilkman et al., 2000; Sudo et al., 2001). The left and right sides of each ROI were quantified separately for all brain regions.

Statistical analyses. The changes in the BP values of $\left[{ }^{11} \mathrm{C}\right] \mathrm{FLB} 457$ in different conditions were analyzed using an rmANOVA model with two within-subject factors, task (baseline, zero-back, two-back) and hemisphere (left, right), and with presentation order as a between-subject factor. The main effect of task order was nonsignificant in all regions 
Plane 10

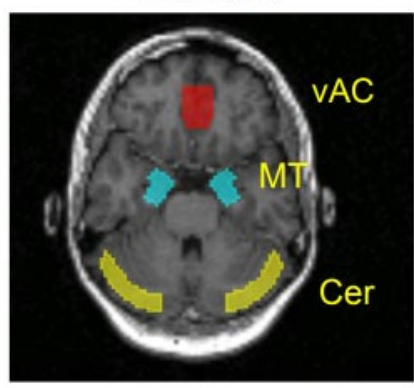

Plane 18
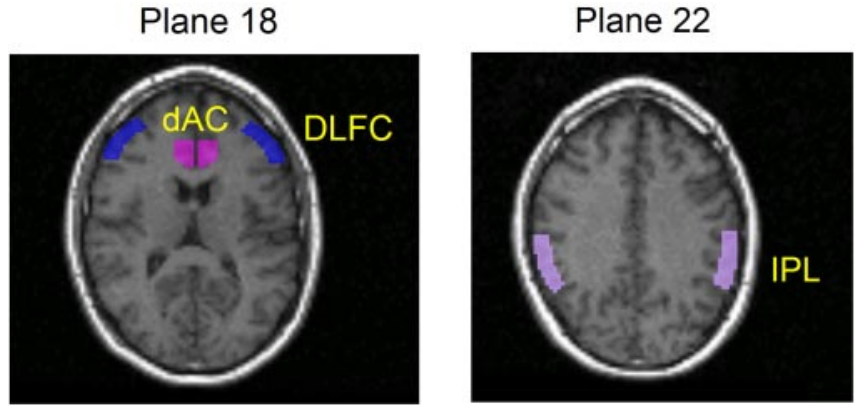

Figure 1. Visualization of the size, shape, and localization of the ROIs. vAC, Ventral $A C ; d A C$, dorsal AC; Cer, cerebellum.

studied, and the only statistical trend ( $p=0.10$ ) was found in the VLFC. Because the order-by-task interaction was significant in the ventral AC $(p<0.05)$, we used the order variable as a grouping factor consistently in all rmANOVAs following a recommendation for counterbalanced repeated-measures designs (Pollatsek and Well, 1995). Six independent rmANOVAs were performed, each including all three task conditions and both hemispheres of the ROI. To minimize sequel testing and, thus, to control for type I error, the contrast testing procedure was continued only when the main effect of the task or the task-by-hemisphere interaction was statistically significant. The left and right sides were eventually tested separately only if the task-by-hemisphere interaction was significant. No multiple-comparison correction was used for the ROI analysis, because the independent confirmatory voxel-based analysis with an inherent correction for multiple comparisons was used to strengthen the reliability of the results. To examine possible associations between task performance and task-related change in the BP of $\left[{ }^{11} \mathrm{C}\right] \mathrm{FLB} 457$, correlation analyses were performed. Four different variables for both the two-back and the zero-back task were used: average reaction times (RTs), sum of errors during tasks, SD of reaction times, and SD of errors. The SD variables, reflecting the stability of performance, were calculated using RTs and error rates of 90 stimulus blocks. Each of these four variables was correlated with the task-related changes in BP values (task-related BP minus resting state BP) by using partial correlations that control for differences in the injected mass of FLB 457. Because of the numerous independent analyses, these correlation analyses were intended to be purely explorative without multiple-comparison correction. Because the amount of injected ligand is critical for the validity of the results when using a high-affinity ligand such as $\left[{ }^{11}\right.$ C]FLB 457 (Asselin et al., 2003; Olsson et al., 2004), we assessed the possible associations of betweencondition differences in the injected masses of FLB 457 with corresponding between-condition differences in the BP values by using Pearson's correlation analyses. $\alpha$ level was set to 0.05 in all statistical analyses.

Voxel-based receptor mapping analysis. The confirmatory voxel-based statistical analysis was conducted as described previously (Hagelberg et al., 2004), using parametric images generated by a procedure shown to be valid and reproducible for $\left[{ }^{11} \mathrm{C}\right]$ FLB 457 (Sudo et al., 2001). Briefly, parametric images were calculated using Receptor Parametric Mapping software (Medical Research Council Cyclotron and PET Unit, Hammersmith Hospital, London, UK) (Gunn et al., 1997) based on a simplified reference tissue model. The preprocessing and statistical analyses of parametric images were performed using Statistical Parametric Mapping (Friston et al., 1995) software, version 99, and MatLab 6.1 for Windows (MathWorks, Natick, MA). Spatial normalization was done using summed images and a ligand-specific template for $\left[{ }^{11} \mathrm{C}\right] \mathrm{FLB} 457$ (Hagelberg et al., 2004). After spatial normalization, the parametric images were smoothed using a $10 \mathrm{~mm}$ Gaussian filter. The confirmatory analysis using small volume correction was confined to the same regions as the ROI analysis. The volumes of interest (VOIs) defining the search volume of analysis were drawn using Imadeus (version 1.50; Forima) on the MRI template image representing the common stereotactic space in accordance with the Montreal Neurological Institute (MNI) space. To ensure the common stereotactic space, the mean image of the spatially normalized MRIs of the study sample was used as the anatomical template instead of a single spatially normalized magnetic resonance image. Spatial normalization of the MRIs was performed using SPM99 and time constant T1-weighted MRI template with default settings. The single binary image created of these VOIs was used with an explicit masking procedure in the SPM analysis. The statistical testing was based on subtraction analysis and $t$ contrast. A $p$ value $<0.05$ and corrected for multiple comparisons was considered as significant. The localization of the results of the SPM analysis was made using the MNI space utility (http://www.ihb.spb.ru/ $\sim$ pet_lab/MSU/MSUMain.html), which first converts the MNI coordinates given by SPM to Talairach coordinates using nonlinear transformation (Brett et al., 2002) (http://www.mrc-cbu.cam.ac.uk/Imaging/ Common/mnispace.shtml) and then identifies each voxel by the anatomical labels presented in the Talairach Daemon database (Lancaster et al., 2000).

\section{Results}

Behavioral results indicated that, despite the considerable duration of the sustained attention and WM tasks, the participants' mean reaction times remained quite stable throughout the experiment (Fig. 2). Also, the average \pm SD rates of correct responses (98.71 $\pm 1.01 \%$ for the vigilance task and $93.68 \pm 3.61 \%$ for the WM task) indicated that both tasks were quite manageable for the subjects. As expected, both the reaction time and the accuracy measures showed that the WM task represented the more demanding condition.

rmANOVA of the ROI-based BP values of $\left[{ }^{11} \mathrm{C}\right] \mathrm{FLB} 457$ showed a significant main effect of the task in the VLFC, the MT, and the ventral AC, indicating task-related changes in BP values. In pairwise contrasts, we found an $11.3 \%$ (left, 9.4\%; right, $13.2 \%)$ average decrease of BP in the VLFC bilaterally $\left(F_{(1,6)}=\right.$ $14.89 ; p=0.008)$ and a $14 \%$ decrease in the left $\operatorname{MT}\left(F_{(1,6)}=\right.$ 14.28 ; $p=0.009$ ) during the WM task compared with the vigilance task. In the left MT, the WM task induced a 10.9\% decrease in $\mathrm{BP}$ compared with the baseline, and this change was also highly significant $\left(F_{(1,6)}=40.47 ; p=0.001\right)$. Individual BP values related to WM-specific findings are presented in Figure 3. In the left ventral $\mathrm{AC}$, the vigilance task induced an $11 \%$ decrease in $\mathrm{BP}$ compared with the baseline condition $\left(F_{(1,6)}=16.88 ; p=0.006\right)$, whereas the WM task induced an $8.5 \%$ decrease in BP from the baseline level $\left(F_{(1,6)}=13.49 ; p=0.01\right)$. The main effect of the task was not significant in the inferior parietal lobe $\left(F_{(2,12)}=1.01\right.$; $p=0.39)$, in the dorsal AC $\left(F_{(2,12)}=0.97 ; p=0.41\right)$, or in the dorsolateral frontal cortex $\left(F_{(2,12)}=0.63 ; p=0.55\right)$. Group-level results of the ROI analysis are presented in Table 1 . An independent voxel-based receptor parametric mapping analysis (Table 2) confirmed the results of the ROI analysis and enabled detailed visualization of the effects (Fig. 4).

The correlation analyses exploring possible associations be- 
tween task performance and task-related changes in BP values revealed two significant correlations. Average reaction times in the WM task correlated with the WM taskrelated change in BP in the right VLFC $(r=$ $0.68 ; p=0.023$ ), and the SD of errors during the WM task correlated with the WM taskrelated change in $\mathrm{BP}$ in the left ventral $\mathrm{AC}$ $(r=0.67 ; p=0.024)$. The direction of these associations was such that reaction times shortened and variability of errors decreased when BP during the task decreased. Other correlation analyses between BP changes and behavioral variables yielded clearly nonsignificant results $(p>0.1)$.

Correlation analyses testing the association of between-condition differences in the injected masses of FLB 457 with the corresponding between-condition differences in the BP revealed no significant results ( $r=-0.21$ to $0.38 ; p=0.22$ to 0.51 ).

\section{Discussion}

Our study revealed that the BP of $\left[{ }^{11} \mathrm{C}\right] \mathrm{FLB} 457$ decreased in the left MT area and the VLFC bilaterally during the WM task compared with the sustained attention task, which was fully comparable in terms of the stimuli and the motor response demands. In addition, both the sustained attention and the WM tasks induced a decrease in $\mathrm{BP}$ in the ventral $\mathrm{AC}$ compared with the resting baseline. To our knowledge, this is the first PET study documenting effects of cognitive performance on cortical dopaminergic function in humans.

In line with the binding competition principle (for review, see Laruelle, 2000; Laruelle and Huang, 2001), the changes in the BP of benzamides reflect changes in the concentration of endogenous dopamine. Also, recent studies using $\mu$-receptor agonist alfentanile intervention in humans (Hagelberg et al., 2004) and intervention with the dopamine releaser amphetamine $(2 \mathrm{mg} / \mathrm{kg})$ in primates (Chou et al., 2000) suggest that BP of [ $\left.{ }^{11} \mathrm{C}\right] \mathrm{FLB} 457$ changes in accordance with the competition principle. However, another study with primates failed to show an effect of methamphetamine $(1 \mathrm{mg} / \mathrm{kg})$ on the binding of $\left[{ }^{11} \mathrm{C}\right] \mathrm{FLB} 457$ (Okauchi et al., 2001). Their negative results may, however, be caused by the use of approximately threefold doses of ketamine in anesthesia, which in itself releases dopamine in the cortical regions (Verma and Moghaddam, 1996; Lindefors et al., 1997), and the smaller dose of methamphetamine, which also has a weaker potency than amphetamine to increase the dopamine concentration in the prefrontal cortex in rats (Shoblock et al., 2003, 2004). The very high affinity of $\left[{ }^{11} \mathrm{C}\right]$ FLB 457 should not be a concern here, because under conditions in which equilibrium prevails and tracer doses are administered, the affinity of the tracer does not affect its sensitivity to competition with endogenous dopamine (Chou et al., 2000; Fujita et al., 2000; Laruelle, 2000; Laruelle and Huang, 2001). However, as critically pointed out by Laruelle (2000), there are also other factors apart from direct competition with dopamine that could affect the BP of a radioligand. It is not possible to exclude the
Vigilance task

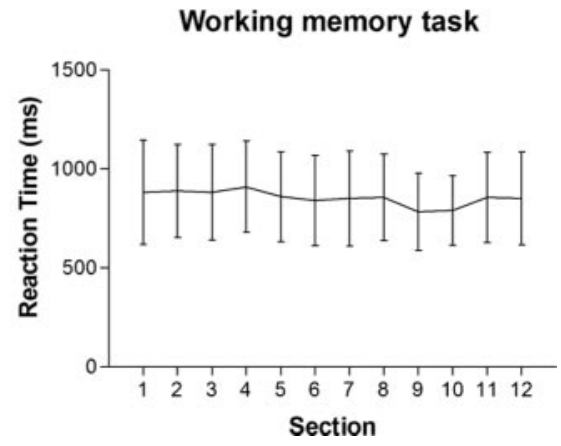

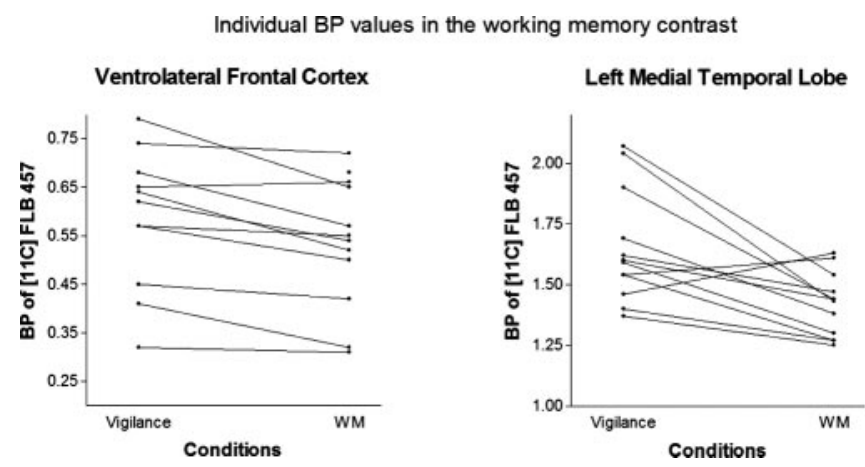

Figure 3. Individual BP values of $\left[{ }^{11} \mathrm{C}\right] \mathrm{FLB} 457$ related to working memory-specific findings. Individual BP values in the ventrolateral frontal cortex and in the left medial temporal lobe during the vigilance and WM conditions are presented.

effects of indirect mechanisms, such as agonist-mediated internalization of $\mathrm{D}_{2}$ receptors (Chugani et al., 1988), on the BP of $\left[{ }^{11} \mathrm{C}\right] \mathrm{FLB}$ 457. Because all PET scans of each subject were performed during the same day in an order dictated by the counterbalancing scheme, quite fast recovery of mechanisms affecting the $\mathrm{BP}$ of $\left[{ }^{11} \mathrm{C}\right] \mathrm{FLB} 457$ is required to achieve the results of the present study. In this time frame, notable changes in $B_{\max }$ caused by receptor internalization are not very probable, and we thus
Table 1. Group-level results of the ROI analysis of [ $\left.{ }^{11} \mathrm{C}\right] \mathrm{FLB} 457$

\begin{tabular}{|c|c|c|c|c|c|c|}
\hline & \multicolumn{2}{|c|}{ Baseline } & \multicolumn{2}{|c|}{ Vigilance } & \multicolumn{2}{|l|}{ WM } \\
\hline & Mean & SD & Mean & SD & Mean & SD \\
\hline \multicolumn{7}{|l|}{ Ventral AC } \\
\hline Right & 0.95 & 0.18 & 0.93 & 0.17 & 0.87 & 0.16 \\
\hline Left & 0.90 & 0.18 & 0.80 & 0.17 & 0.82 & 0.19 \\
\hline \multicolumn{7}{|l|}{ Dorsal AC } \\
\hline Right & 0.92 & 0.22 & 0.80 & 0.20 & 0.81 & 0.20 \\
\hline Left & 0.80 & 0.14 & 0.84 & 0.18 & 0.82 & 0.28 \\
\hline \multicolumn{7}{|l|}{ VLFC } \\
\hline Right & 0.57 & 0.16 & 0.62 & 0.15 & 0.54 & 0.14 \\
\hline Left & 0.58 & 0.17 & 0.60 & 0.18 & 0.54 & 0.16 \\
\hline \multicolumn{7}{|l|}{ DLFC } \\
\hline Right & 0.62 & 0.15 & 0.59 & 0.15 & 0.61 & 0.11 \\
\hline Left & 0.60 & 0.14 & 0.60 & 0.17 & 0.61 & 0.14 \\
\hline \multicolumn{7}{|l|}{ IPL } \\
\hline Right & 0.77 & 0.23 & 0.74 & 0.22 & 0.75 & 0.27 \\
\hline Left & 0.85 & 0.27 & 0.84 & 0.27 & 0.81 & 0.22 \\
\hline \multicolumn{7}{|l|}{ MT } \\
\hline Right & 1.58 & 0.23 & 1.50 & 0.20 & 1.46 & 0.27 \\
\hline Left & 1.59 & 0.27 & 1.65 & 0.23 & 1.42 & 0.13 \\
\hline
\end{tabular}

The mean BP values with SDs of $\left[{ }^{11} \mathrm{C}\right] \mathrm{FLB} 457$ for both hemispheres during all conditions are shown. 
Table 2. Results of the voxel-based statistical analysis

\begin{tabular}{|c|c|c|c|c|c|c|c|c|}
\hline \multirow[b]{2}{*}{ Abbreviation } & \multirow[b]{2}{*}{ Anatomic region } & \multirow[b]{2}{*}{ Subregions } & \multicolumn{3}{|c|}{ MNI coordinates } & \multirow[b]{2}{*}{ Cluster size } & \multirow[b]{2}{*}{$t$ value of peak voxel } & \multirow[b]{2}{*}{$p$ value } \\
\hline & & & $x$ & $y$ & $z$ & & & \\
\hline \multicolumn{9}{|c|}{ Working memory-vigilance contrast } \\
\hline VLFC & Left inferior frontal gyrus & BA45, BA46, BA47 & -50 & 36 & 0 & 407 & 3.27 & 0.008 \\
\hline VLFC & Right inferior frontal gyrus & BA45, BA47 & 56 & 32 & 6 & 356 & 3.13 & 0.02 \\
\hline MT & Left medial temporal lobe & amygdala, hippocampus & -24 & -2 & -34 & 378 & 3.17 & 0.01 \\
\hline \multicolumn{9}{|c|}{ Working memory-baseline contrast } \\
\hline$A C$ & Anterior cingulate & BA32, BA25, BA10, BA11 & -2 & 28 & -20 & 476 & 5.71 & $<0.001$ \\
\hline \multicolumn{9}{|c|}{ Vigilance-baseline contrast } \\
\hline$A C$ & Anterior cingulate & $\mathrm{BA} 32, \mathrm{BA25}, \mathrm{BA10}, \mathrm{BA} 11$ & -10 & 42 & -10 & 297 & 3.53 & 0.001 \\
\hline
\end{tabular}

The results of all three contrasts are presented. The anatomical regions, the Brodmann areas, the Talairach coordinates, the extents of the clusters, and the $t$ values of the peak voxels and $p$ values of the clusters are given.

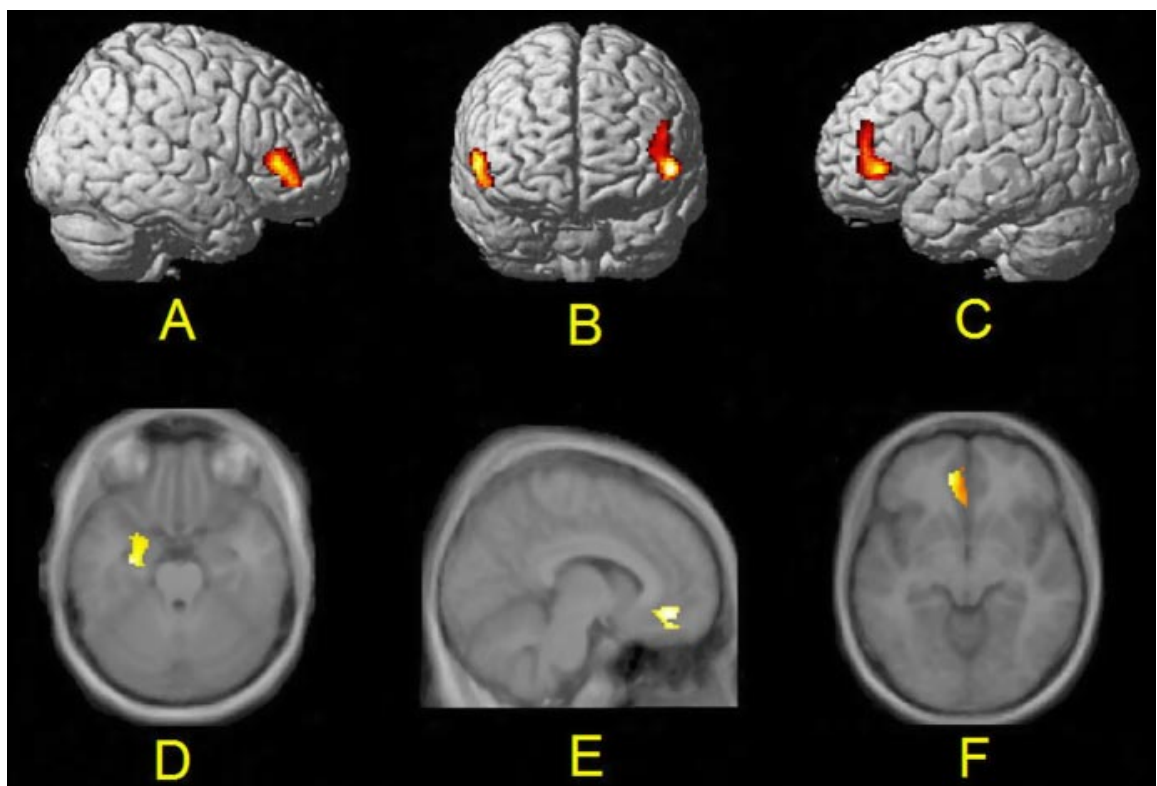

Figure 4. Visualization of a voxel-based statistical analysis. Compared with the vigilance task, the BP of $\left[{ }^{11} \mathrm{C}\right] \mathrm{FLB} 457$ decreased during the working memory task bilaterally in the VLFC (left, $p=0.008$; right, $p=0.02)(\boldsymbol{A}-\boldsymbol{C}$ ) and in the left medial temporal lobe $(p<0.01)(\boldsymbol{D})$. Compared with the resting state baseline, both the vigilance task $(p=0.001)(\boldsymbol{E})$ and the working memory task $(p<0.001)(F)$ induced a decrease in the BP of [ $\left.{ }^{11} \mathrm{C}\right] \mathrm{FLB} 457$ in the left ventral AC. All $p$ values have been corrected for multiple comparisons. The results are visualized on a brain model (top) and on an average MRI template image (bottom) and presented in line with the neurological convention (right is right).

presume that the changes in BP reflect mainly increased competition between endogenous dopamine and the radioligand. Because the alternative explanations are basically driven by the increase in the dopamine concentration, our results suggest that attention and WM task performances in man are associated with regionally specific increases in dopamine release.

There are some methodological issues that should be considered when evaluating the validity of the task-related changes in the BP of $\left[{ }^{11} \mathrm{C}\right]$ FLB 457 observed in this study. The BP measured using the reference tissue method is not affected by any taskrelated stable effects on cerebral blood flow, because the method does not assume the flow to be equal in the region of interest and in the reference region (Slifstein and Laruelle, 2001). However, it should be noted that the method can yield an artifactual decrease in $\mathrm{BP}$ if there are marked changes in the flow during the PET scanning (Dagher et al., 1998; Laruelle, 2000). This is unlikely during the $n$-back tasks used in this study, because the tasks were initiated before the scanning to reach a stable performance level, and the performance was continued without interruption during the entire scanning period. No marked habituation effects were expected either, because the subjects were confronted with continuously varying stimulus sequences. The stable behavioral per- formance observed during the tasks supports this conclusion (Fig. 2). There is also evidence that, because of the very high affinity, the mass of the injected ligand might have a considerable impact on the quantification of $\left[{ }^{11} \mathrm{C}\right] \mathrm{FLB} 457$ (Asselin et al., 2003; Olsson et al., 2004). This potential confounder can be excluded, because correlation analyses showed that the between-condition differences in the injected quantity of FLB 457 do not explain the between-condition differences in BP. One should note that the potential effects of the accumulation of active and cold tracer as well as the potential transfer effects from preceding tasks were eliminated by the fully counterbalanced study design.

Both the WM and the vigilance tasks induced dopamine release in the AC compared with the baseline. However, the effect was restricted to the most ventral part of the AC (BA 25 and the ventral parts of BA 32) (Fig. 4). It was most probably caused by affective and arousal-related factors (Bush et al., 2000) involved in the tasks, because cognitive functions are suggested to be associated with the dorsal parts of the AC (Vogt et al., 1992; Bush et al., 2000). Nevertheless, dopamine might have a functional role in the left ventral AC, because correlation analysis suggested that increased dopamine release was associated with smaller variation in errors during the long-standing WM task.

The AC has reciprocal connections with the amygdala, and it has been suggested that the amygdala and the AC work in tandem, especially in processing motivational and emotional information (Vogt et al., 1992). It is of interest here that inhibition of the amygdaloid dopamine transmission impairs learning and memory functions in rats (Greba et al., 2001) and that both reading and WM tasks induce dopamine release bilaterally in the amygdala in epileptic patients (Fried et al., 2001). Interestingly, in our study, dopamine release in the MT regions, including the amygdala and the hippocampus, was only seen in the left hemisphere and only during the WM task, which suggests more specific involvement in verbal memory.

During the WM task, increased dopamine release was seen bilaterally in the VLFC, mainly in BA 45 and 44. In the left hemisphere, the effect extended to the ventral parts of BA 46 (Fig. 4). The central role of dopaminergic neurotransmission in cognitive tasks calling for WM and executive functions is beyond dispute 
(Goldman-Rakic et al., 1997) (for review, see Arnsten, 1998; Robbins, 2000). The direct involvement of dopamine release in the prefrontal cortex in WM-like tasks was demonstrated using in vivo microdialysis during a delayed alternation task in primates (Watanabe et al., 1997) and in a delayed response task in rats (Phillips et al., 2004). The effects of dopaminergic drugs on WM performance have been demonstrated in humans (Müller et al., 1998; Mehta et al., 1999), but it is unclear in which brain areas these drug effects take place. Our results suggest that, in the VLFC, which is a region involved in WM in humans (Braver et al., 1997; Honey et al., 2002), dopamine might play a role in the regulation of WM function. Interestingly, the results by Phillips et al. (2004) indicated that dopamine release in the prefrontal cortex predicts the accuracy of memory performance in rats. Our preliminary correlation analysis, on the other hand, suggested that the dopamine release induced by the WM task in the right VLFC was associated with performance speed in the WM task.

With regard to the previous $\mathrm{rCBF}$ studies on verbal WM in humans, it is of interest to note only partial overlap with our results. The previous $\mathrm{rCBF}$ experiments have shown activations widely in the prefrontal cortex (BA 44, 46, 6, and 9) and the inferior parietal lobe (BA 40) during WM tasks (for review, see Cabeza and Nyberg, 2000). However, we saw no evidence of increased dopamine release in the dorsal parts of the lateral frontal cortex (dorsal BA 46, ventral BA 9) or in the inferior parietal lobe (corresponding mainly to BA 40) during either the vigilance or the WM task. Although the BP estimates (Table 1) suggest that there are practically no effects in the DLFC or IPL, it is, nevertheless, possible that the sensitivity of the methodology and the signal variability in these low-binding regions might have prevented the detection of some effects. However, we did observe changes in areas (VLFC) with comparable baseline BP values.

In general, dopaminergic activity is considered to contribute to protection against interfering stimuli and, in integrative processes, selection of the most significant input of information relevant to the context of behavior (Durstewitz et al., 1999; Nieoullon, 2002). Moreover, neural network simulation models of prefrontal cortical function have suggested that at optimal levels of $\mathrm{D}_{1}$ receptor stimulation, active $\mathrm{WM}$ representations become more robust, whereas background activity becomes depressed (Durstewitz and Seamans, 2002). Although a dopamine $\mathrm{D}_{2}$ receptor ligand was used in this study, our results do not indicate involvement of $\mathrm{D}_{2}$ receptors in $\mathrm{WM}$, but rather provide an indirect measure of the changes in the concentration of intrasynaptic dopamine (Laruelle, 2000). However, because there are no studies using simultaneous microdialysis and $\left[{ }^{11} \mathrm{C}\right] \mathrm{FLB} 457$ measurements, the quantitative relationship between a change in BP and the concentration of endogenous dopamine is yet unestablished.

In summary, our results indicate that a distributed, regionally specific frontal-temporal dopaminergic network is involved in verbal working memory performance in humans. Methodologically, our study demonstrates the potential of the novel PET and $\left[{ }^{11} \mathrm{C}\right] \mathrm{FLB} 457$ imaging approach in tracking the cortical dopaminergic correlates of human cognition in vivo. In future studies, novel analysis methods with better time resolution (Pappata et al., 2002, Alpert et al., 2003) might enable the detection of more transient changes in the concentration of cortical dopamine, further enhancing the usability of this approach.

\section{References}

Alpert NM, Badgaiyan RD, Livni E, Fischman AJ (2003) A novel method for noninvasive detection of neuromodulatory changes in specific neurotransmitter systems. NeuroImage 19:1049-1060.
Arnsten AF (1998) Catecholamine modulation of prefrontal cortical cognitive function. Trends Cogn Sci 2:436-447.

Asselin MC, Montgomery AJ, Hume SP, Cunningham VJ, Grasby PM (2003) Quantification of PET studies with the very high affinity D2/D3 receptor ligand $\left[{ }^{11} \mathrm{C}\right]$ FLB-457: effects of co-injected stable FLB-457. Mol Imaging Biol 5:98.

Bergström M, Eriksson L, Bohm C, Blomqvist G, Litton J (1983) Correction for scattered radiation in a ring detector positron camera by integral transformation of the projections. J Comput Assist Tomogr 7:42-50.

Braver TS, Cohen JD, Nystrom LE, Jonides J, Smith EE, Noll DC (1997) A parametric study of prefrontal cortex involvement in human working memory. NeuroImage 5:49-62.

Brett M, Johnsrude IS, Owen AM (2002) The problem of functional localization in the human brain. Nat Rev Neurosci 3:243-249.

Bush G, Luu P, Posner MI (2000) Cognitive and emotional influences in anterior cingulate cortex. Trends Cogn Sci 4:215-222.

Cabeza R, Nyberg L (2000) Imaging cognition II: an empirical review of 275 PET and fMRI studies. J Cogn Neurosci 12:1-47.

Chou Y-H, Halldin C, Farde L (2000) Effect of amphetamine on extrastriatal D2 dopamine receptor binding in the primate brain: a PET study. Synapse 38:138-143.

Chugani DC, Ackermann RF, Phelps ME (1988) In vivo $\left[{ }^{3} \mathrm{H}\right]$ spiperone binding: evidence for accumulation in corpus striatum by agonistmediated receptor internalization. J Cereb Blood Flow Metab 8:291-303.

Dagher A, Gunn R, Lockwood G, Cunningham VJ, Grasby PM, Brooks DJ (1998) Measuring neurotransmitter release with PET: methodological issues. In: Quantitative functional brain imaging with positron emission tomography (Carlson R, Daube-Withespoon ME, Herscovitch P, eds), pp 449-454. San Diego: Academic.

Delforge J, Bottlaender M, Loc'h C, Guenther I, Fuseau C, Bendriem B, Syrota A, Maziere B (1999) Quantitation of extrastriatal D2 receptors using a very high-affinity ligand (FLB 457) and the multi-injection approach. J Cereb Blood Flow Metab 19:533-546.

Durstewitz D, Seamans JK (2002) The computational role of dopamine D1 receptors in working memory. Neural Netw 15:561-572.

Durstewitz D, Kelc M, Gunturkun O (1999) A neurocomputational theory of the dopaminergic modulation of working memory functions. J Neurosci 19:2807-2822.

Farde L, Suhara T, Nyberg S, Karlsson P, Nakashima Y, Hietala J, Halldin C (1997) A PET study of [C-11]FLB 457 binding to extrastriatal D-2 dopamine receptors in healthy subjects and antipsychotic drug-treated patients. Psychopharmacology 133:396-404.

Fletcher PC, Henson RN (2001) Frontal lobes and human memory: insights from functional neuroimaging. Brain 124:849-881.

Fried I, Wilson CL, Morrow JW, Cameron KA, Behnke ED, Ackerson LC, Maidment NT (2001) Increased dopamine release in the human amygdala during performance of cognitive tasks. Nat Neurosci 4:201-206.

Friston KJ, Holmes AP, Worsley KJ, Poline J-B, Frith CD, Frackowiak RSJ (1995) Statistical parametric maps in functional imaging: a general linear approach. Hum Brain Mapp 2:189-210.

Fujita M, Verhoeff NP, Varrone A, Zoghbi SS, Baldwin RM, Jatlow PA, Anderson GM, Seibyl JP, Innis RB (2000) Imaging extrastriatal dopamine D2 receptor occupancy by endogenous dopamine in healthy humans. Eur J Pharmacol 387:179-188.

Goldman-Rakic PS (1996) Regional and cellular fractionation of working memory. Proc Natl Acad Sci USA 93:13473-13480.

Goldman-Rakic PS, Bergson C, Mrzljak L, Williams GV (1997) Dopamine receptors and cognitive function in nonhuman primates. In: The dopamine receptors (Neve KA, Neve RL, eds), pp 499-522. Totowa, NJ: Humana.

Greba Q, Gifkins A, Kokkinidis L (2001) Inhibition of amygdaloid dopamine D2 receptors impairs emotional learning measured with fearpotentiated startle. Brain Res 899:218-226.

Gunn RN, Lammertsma AA, Hume SP, Cunningham VJ (1997) Parametric imaging of ligand-receptor binding using a simplified reference region model. NeuroImage 6:279-287.

Haarala C, Aalto S, Hautzel H, Julkunen L, Rinne JO, Laine M, Krause B, Hamalainen H (2003) Effects of a $902 \mathrm{MHz}$ mobile phone on cerebral blood flow in humans: a PET study. NeuroReport 14:2019-2023.

Hagelberg N, Aalto S, Kajander J, Oikonen V, Hinkka S, Någren K, Hietala J, Scheinin H (2004) Alfentanil increases cortical dopamine D2/D3 receptor binding in healthy subjects. Pain 109:86-93. 
Hall H, Farde L, Halldin C, Hurd YL, Pauli S, Sedvall G (1996) Autoradiographic localization of extrastriatal D2-dopamine receptors in the human brain using $\left[{ }^{125} \mathrm{I}\right]$ epidepride. Synapse 23:115-123.

Hirvonen J, Aalto S, Lumme V, Nagren K, Kajander J, Vilkman H, Hagelberg N, Oikonen V, Hietala J (2003) Measurement of striatal and thalamic dopamine D2 receptor binding with ${ }^{11} \mathrm{C}$-raclopride. Nucl Med Commun 24:1207-1214.

Honey GD, Fu CH, Kim J, Brammer MJ, Croudace TJ, Suckling J, Pich EM, Williams SC, Bullmore ET (2002) Effects of verbal working memory load on corticocortical connectivity modeled by path analysis of functional magnetic resonance imaging data. NeuroImage 17:573-582.

Ito H, Sudo Y, Suhara T, Okubo Y, Halldin C, Farde L (2001) Error analysis for quantification of [(11)C]FLB 457 binding to extrastriatal D(2) dopamine receptors in the human brain. NeuroImage 13:531-539.

Kaasinen V, Aalto S, Någren K, Rinne JO (2004) Expectation of caffeine induces dopaminergic responses in humans. Eur J Neurosci 19:2352-2356.

Koepp MJ, Gunn RN, Lawrence AD, Cunningham VJ, Dagher A, Jones T, Brooks DJ, Bench CJ, Grasby PM (1998) Evidence for striatal dopamine release during a video game. Nature 393:266-268.

Lammertsma AA, Hume SP (1996) Simplified reference tissue model for PET receptor studies. NeuroImage 4:153-158.

Lancaster JL, Woldorff MG, Parsons LM, Liotti M, Freitas CS, Rainey L, Kochunov PV, Nickerson D, Mikiten SA, Fox PT (2000) Automated Talairach atlas labels for functional brain mapping. Hum Brain Mapp 10:120-131.

Laruelle M (2000) Imaging synaptic neurotransmission with in vivo binding competition techniques: a critical review. J Cereb Blood Flow Metab 20:423-451.

Laruelle M, Huang Y (2001) Vulnerability of positron emission tomography radiotracers to endogenous competition. New insights. Q J Nucl Med 45:124-138.

Lewellen TK, Kohlmyer SG, Miyaoka RS, Kaplan MS, Sterans CW, Schubert SF (1996) Investigation of the performance of the general electric ADVANCE positron emission tomograph in 3D mode. IEEE Trans Nucl Sci 43:2199-2206.

Lindefors N, Barati S, O'Connor WT (1997) Differential effects of single and repeated ketamine administration on dopamine, serotonin and GABA transmission in rat medial prefrontal cortex. Brain Res 759:205-212.

Mehta MA, Sahakian BJ, McKenna PJ, Robbins TW (1999) Systemic sulpiride in young adult volunteers simulates the profile of cognitive deficits in Parkinson's disease. Psychopharmacology 146:162-174.

Müller U, von Cramon Y, Pollmann S (1998) D1-versus D2-receptor modulation of human visuospatial working memory in humans. J Neurosci 18:2720-2728.

Nieoullon A (2002) Dopamine and the regulation of cognition and attention. Prog Neurobiol 67:53-83.

Okauchi T, Suhara T, Maeda J, Kawabe K, Obayashi S, Suzuki K (2001) Effect of endogenous dopamine on endogenous dopamine on extrastriated [(11)C]FLB 457 binding measured by PET. Synapse 41:87-95.
Olsson H, Halldin C, Swahn CG, Farde L (1999) Quantification of [ $\left.{ }^{11} \mathrm{C}\right] \mathrm{FLB}$ 457 binding to extrastriatal dopamine receptors in the human brain. J Cereb Blood Flow Metab 19:1164-1173.

Olsson H, Halldin C, Farde L (2004) Differentiation of extrastriatal dopamine D2 receptor density and affinity in the human brain using PET. NeuroImage 22:794-803.

Pappata S, Dehaene S, Poline JB, Gregoire MC, Jobert A, Delforge J, Frouin V, Bottlaender M, Dolle F, Di Giamberardino L, Syrota A (2002) In vivo detection of striatal dopamine release during reward: a PET study with $\left[{ }^{11} \mathrm{C}\right]$ raclopride and a single dynamic scan approach. NeuroImage 16:1015-1027.

Phillips AG, Ahn S, Floresco SB (2004) Magnitude of dopamine release in medial prefrontal cortex predicts accuracy of memory on a delayed response task. J Neurosci 24:547-553.

Pollatsek A, Well AD (1995) On the use of counterbalanced designs in cog nitive research: a suggestion for a better and more powerful analysis. J Exp Psychol Learn Mem Cogn 21:785-794.

Pruessner JC, Champagne F, Meaney MJ, Dagher A (2004) Dopamine release in response to a psychological stress in humans and its relationship to early life maternal care: a positron emission tomography study using $\left[{ }^{11} \mathrm{C}\right]$ raclopride. J Neurosci 24:2825-2831.

Robbins TW (2000) Chemical neuromodulation of frontal-executive functions in humans and other animals. Exp Brain Res 133:130-138.

Shoblock JR, Sullivan EB, Maisonneuve IM, Glick SD (2003) Neurochemical and behavioral differences between D-methamphetamine and D-amphetamine in rats. Psychopharmacology 165:359-369.

Shoblock JR, Maisonneuve IM, Glick SD (2004) Differential interactions of desipramine with amphetamine and methamphetamine: evidence that amphetamine releases dopamine from noradrenergic neurons in the medial prefrontal cortex. Neurochem Res 29:1437-1442.

Slifstein M, Laruelle M (2001) Models and methods for derivation of in vivo neuroreceptor parameters with PET and SPECT reversible radiotracers. Nucl Med Biol 28:595-608.

Sudo Y, Suhara T, Inoue M, Ito H, Suzuki K, Saijo T, Halldin C, Farde L (2001) Reproducibility of $\left[{ }^{11} \mathrm{C}\right]$ FLB 457 binding in extrastriatal regions. Nucl Med Commun 22:1215-1221.

Verma A, Moghaddam B (1996) NMDA receptor antagonists impair prefrontal cortex function as assessed via spatial delayed alternation performance in rats: modulation by dopamine. J Neurosci 16:373-379.

Vilkman H, Kajander J, Nagren K, Oikonen V, Syvalahti E, Hietala J (2000) Measurement of extrastriatal D2-like receptor binding with $\left[{ }^{11} \mathrm{C}\right]$ FLB 457-a test-retest analysis. Eur J Nucl Med 27:1666-1673.

Vogt BA, Finch DM, Olson CR (1992) Functional heterogeneity in cingulate cortex: the anterior executive and posterior evaluative regions. Cereb Cortex 2:435-443

Watanabe M, Kodama T, Hikosaka K (1997) Increase of extracellular dopamine in primate prefrontal cortex during a working memory task. J Neurophysiol 78:2795-2798 